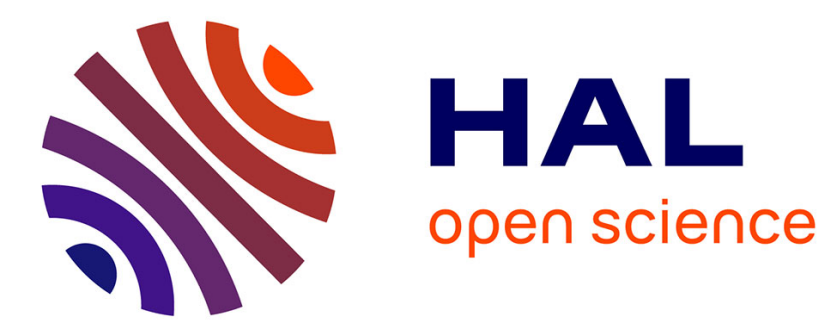

\title{
Unpacking the management of Oligo-coopetition strategies in the absence of a moderating third party
}

Frédéric Le Roy, Sea Matilda Bez, Johanna Gast

\section{To cite this version:}

Frédéric Le Roy, Sea Matilda Bez, Johanna Gast. Unpacking the management of Oligo-coopetition strategies in the absence of a moderating third party. Industrial Marketing Management, 2021, 98, pp.125-137. 10.1016/j.indmarman.2021.08.004 . hal-03349671

\section{HAL Id: hal-03349671 \\ https://hal.science/hal-03349671}

Submitted on 20 Sep 2021

HAL is a multi-disciplinary open access archive for the deposit and dissemination of scientific research documents, whether they are published or not. The documents may come from teaching and research institutions in France or abroad, or from public or private research centers.
L'archive ouverte pluridisciplinaire HAL, est destinée au dépôt et à la diffusion de documents scientifiques de niveau recherche, publiés ou non, émanant des établissements d'enseignement et de recherche français ou étrangers, des laboratoires publics ou privés. 


\section{UnPaCking The Management OF Oligo-CoOpetition STRATEgies in the AbSEnCE OF a Moderating Third Party}

\section{INTRODUCTION}

Coopetition, i.e., cooperation among competitors (Brandenburger \& Nalebuff, 1996), started to develop in the 1980s (Hamel, Doz \& Prahalad, 1989) and currently represents a common strategy in most industries (Fernandez, Chiambaretto, Le Roy \& Czakon, 2018; Hoffmann, Lavie, Reuer \& Shipilov, 2018; Czakon, Srivastava, Le Roy, Gnyawali, 2020). Based on the simultaneity of cooperative and competitive elements, coopetition comes with several benefits and risks (Le Roy \& Czakon, 2016). One of the critical challenges associated with coopetition is the question of how to manage this strategy effectively to benefit from its possible positive effects and limit its potential negative consequences (Enberg, 2012; Bengtsson, Raza-Ullah \& Vanyushyn, 2016; Le Roy \& Czakon, 2016; Tidström, 2014).

Therefore, prior research sought to identify management principles and organizational designs that help to manage coopetition successfully. The three main principles to manage coopetition (Le Roy, Fernandez \& Chiambaretto, 2018) are the organizational separation between competitive and cooperative activities (Bengtsson \& Kock, 2000), the individual integration of the coopetitive paradox (Fernandez, Le Roy \& Gnyawali, 2014), and the comanagement of shared activities (Le Roy \& Fernandez, 2015). The organizational designs to manage coopetition depend on projects' risks, costs, and innovativeness (Fernandez, Le Roy \& Chiambaretto, 2018). For projects characterized by low risk, low cost, and low radicalness, coopetitors use so-called Separate Project Teams (SPTs). For projects characterized by high risk, high cost, and high radicalness, coopetitors use Coopetitive Project Teams (CPTs). 
One pitfall of prior research on coopetition management is that these studies examined mainly dyadic coopetition, that is, coopetition involving only two competitors (Bengtsson \& Kock, 2000; Dagnino \& Padula, 2002; Le Roy \& Fernandez, 2015). However, other coopetition forms exist, including oligo-coopetition, meaning coopetition between more than two but a limited number of coopetitors. Oligo-coopetition, a priori, makes the coopetitive relationship more complex (Rouyre \& Fernandez, 2019). Although increasing the number of coopetitors should lead to higher positive additional and synergetic effects (Czakon et al., 2020), the risk of opportunism is also greater (Enberg, 2012). Therefore, the question is how to manage oligo-coopetition strategy successfully.

Only a few studies are dedicated to this question highlighting that the successful management of this oligo-coopetition is a challenging task given the increased complexity (Enberg, 2012; Rouyre \& Fernandez, 2019; Jakobsen, 2020). To deal with this complex coopetitive relationship including multiple partners, coopetitors tend to include a noncompeting neutral third party into their coopetition relationship (Rouyre and Fernandez, 2019; Planko, Chappin, Cramer, \& Hekkert, 2019; Smiljic, 2020). However, there is one problem as such an external third party does not always exist in oligo-coopetition (Enberg, 2012). Therefore, what happens when there is no external third party? How do companies involved in oligo-coopetition strategy manage to obtain benefits while limiting the risk of opportunism? Which organizational design do they use? Which management principles do they apply among the principles of separation, integration, and co-management?

We seek to answer these questions through a qualitative study following the flexible (stepwise) pattern matching approach (Sinkovics, 2018; Bouncken \& Barwinski, 2020; Bouncken, Qiu, \& García, 2021a; Bouncken, Qiu, Sinkovics, \& Kürsten, 2021b) to study coopetitive strategy in oligo-coopetition. We conducted a case study analyzing coopetition strategies employed by one of the world's five major oil companies operating in the oil and 
gas exploration and production (OGEP) market, the Total Group. Our results highlight the use of three different strategies in the oligo-coopetition context: (1) "shareholder" coopetition, (2) "vertical" coopetition, and (3) "combined vertical and horizontal" coopetition. All of these strategies differ in terms of organizational design and applied management principles based on the coopetition project's characteristics in terms of risks, costs and innovativeness.

Our research contributes to the coopetition literature by showing for the first time how companies can successfully manage oligo-coopetition strategies in the absence of a moderating third party. More precisely, first, our research contributes to knowledge on coopetition strategy by showing how three distinct oligo-coopetitive strategies can co-exist on different stages of the value chain (e.g., Chiambaretto \& Dumez, 2016), including vertical (e.g., Lacoste, 2012; Lechner et al., 2016; Soppe et al., 2014) and horizontal (Choi et al., 2010; Hannachi \& Coléno, 2012), with different levels of risk, costs, and innovativeness (Fernandez, Le Roy \& Chiambaretto, 2018; Bez \& Chesbrough, 2020).

Second, we contribute to prior research by showing that three oligo-coopetition strategies co-exist in the same company and how they imply different organizational designs, management principles, and outcomes (Chiambaretto et al., 2020; Rajala \& Tidström, 2017; Tidström \& Rajala, 2016).

The first identified oligo-coopetition strategy that is new relative to dyadic coopetition strategy was named "shareholder" coopetition. "Shareholder" coopetition is applied for lowrisk, low-cost, and non-innovative coopetitive projects. In this case, the more coopetitors are involved the better it is and there are no extra risks as only one company oversees the operational tasks. Cooperation happens only on the strategic level to share costs and risks and not on the operational level. There is no sharing and strong protection of knowledge.

The second strategy of oligo-coopetition is "vertical" coopetition. This strategy enables coopetitors to develop an organizational design limiting knowledge sharing and permitting its 
protection for medium-risk, medium-cost, and medium-innovative coopetitive projects. While coopetitors plug-in their results of their internally performed tasks, there is low sharing and strong protection of knowledge. This second vertical oligo-coopetition strategy works exactly as vertical dyadic coopetition.

The third oligo-coopetition strategy is "combined vertical and horizontal" coopetition for high-risk, high-cost, and highly innovative coopetitive projects. Here, the project is divided in individual tasks. Each task is either delegated to one coopetitor (i.e., traditional vertical coopetition) or to a small group of coopetitors that include only coopetitors with in-depth expertise on the related task (i.e. "sub-CPT"). This result advances prior knowledge of coopetition management by highlighting how companies can outdo the challenge of managing very innovative projects done in oligo-coopetition in the absence of a third-party.

With these three oligo-coopetition strategies and their specific organizational designs, we contribute to prior research by showing that coopetition strategies at multiple levels can coexist and how these levels may interrelate resulting in different organizational designs, management principles, and outcomes (Chiambaretto et al., 2020; Rajala \& Tidström, 2017; Tidström \& Rajala, 2016).

Finally, our research contributes to the literature on coopetition for innovation by highlighting a new view in which a coopetitor has a deep interest in imposing and sharing its technology in high tech sub-tasks. The key organizational success relies on limiting the number of coopetitors involved in the highly innovative, costly, and risky tasks to two or three coopetitors with high expertise.

\section{THEORETICAL FOUNDATIONS}

\subsection{Coopetition: a strategy under tension}

Coopetition is a relationship between two or more firms cooperating in certain business activities while competing in other activities (Bengtsson \& Kock, 2000). Although frequently 
praised in business and management research, coopetition is a paradoxical relationship. The simultaneity of the two contradictory logics of interaction-cooperation and competitionamong at least two firms (Tidström, 2014; Pellegrin-Boucher, Le Roy \& Gurău, 2013) can make coopetitive relationships irrational, inconsistent, or even absurd (Bengtsson, Raza-Ullah \& Vanyushyn, 2016).

De facto, due to coopetition's "inherent contradictory and opposing forces" (Fernandez, Le Roy \& Gnyawali, 2014, p. 224), this strategy is not easy and straightforward and may lead to instability and significant tensions. The critical point is to be able to articulate cooperation for value creation while at the same time competing for value appropriation (Bouncken, Fredrich, $\&$ Kraus, 2020). On the one hand, coopetitors seek to create value by developing additional and synergic effects from cooperation in, for instance, $R \& D$ activities or the sharing of knowledge, resources, and skills (Estrada, Faems \& de Faria, 2016; Le Roy \& Czakon, 2016; Ritala \& Hurmelinna-Laukkanen, 2009; Ritala, 2019). On the other hand, however, coopetitors seek to capture the value created together. They remain competitors and need to be aware of the specific risks associated with competition in coopetition (Bouncken \& Fredrich, 2012; Ritala, Huizingh, Almpanopoulou \& Wijbenga, 2017; Ritala \& HurmelinnaLaukkanen, 2009; Ritala, Golnam \& Wegmann, 2014).

Decisions on how to share and protect technologies, expertise, and knowledge in coopetition represent a significant contributor to the coopetition dilemma. If coopetitors decide to limit coopetitive knowledge sharing to protect their competitive advantage, coopetition benefits may be limited, and the strategy may even be unsuccessful (Fernandez, Chiambaretto, Le Roy \& Czakon, 2018; Gast, Gundolf, Harms \& Collado, 2019). If coopetitors decide to share their knowledge, they may have much higher potential for creating common value, but they take the risk of unwanted knowledge leakage or even skills looting (Fernandez, Chiambaretto, Le Roy \& Czakon, 2018; Gast, Gundolf, Harms \& Collado, 2019; 
Enberg, 2012). If such looting is too severe, coopetition can create more competitive problems for firms than it solves. Coopetition thus gives rise to tensions for firms between the opportunities that it creates and the risks that it poses. An effective management of coopetition is required to ensure both value creation and value appropriation.

\subsection{Management of dyadic coopetition}

\subsubsection{Management principles in dyadic coopetition: separation, integration and co- management}

Coopetitive tensions are linked to the very nature of coopetition. They cannot, therefore, be reduced to zero. To ensure that coopetition creates value, successful coopetition management is required (Le Roy \& Czakon, 2016; Le Roy, Fernandez \& Chiambaretto, 2018). Prior literature on coopetition management identifies three fundamental management principles: the principle of separation, the principle of integration, and the principle of co-management (Le Roy \& Fernandez, 2015).

The principle of organizational separation of cooperative and competitive activities refers to the spatial, functional, or geographical separation of competition and collaboration (Bengtsson \& Kock, 2000; Dowling, Roering, Carlin \& Wisnieski, 1996). For instance, different value chain activities should be split up according to their cooperative or competitive character (Bengtsson \& Kock, 2000). The principle of separation thus seems to offer simple organizational solutions to the challenges of coopetition. However, the application of the separation principle may give rise to new tensions within companies, as employees may no longer understand each other's roles (Le Roy \& Fernandez, 2015; Fernandez Le Roy \& Gnyawali, 2014; Pellegrin-Boucher, Le Roy \& Gurău, 2018).

Therefore, coopetitors' employees must develop a capacity for an individual integration of the coopetition paradox (Le Roy \& Fernandez, 2015; Pellegrin-Boucher, Le Roy \& Gurău, 2018). According to this integration principle, individuals are encouraged to transcend the 
paradox (Chen, 2008) and to develop a coopetitive mindset allowing them to internalize the paradoxical logic of coopetition and efficiently manage the accompanying tensions (Chen, 2008; Gnyawali \& Park, 2011).

While the separation principle concerns the organizational level of coopetitive projects, the integration principle concerns the individual level. Between these two levels, coopetitors have to manage their common activities at the working-group level (Le Roy \& Fernandez, 2015). To do this, they use a third principle named co-management principle: coopetitors implement a dual, equally shared governance structure, a dual management committee, and an equal duplication of management functions. The co-management principle permits both knowledge sharing for value creation and the monitoring of the coopetitor to ensure value appropriation (Fernandez et al., 2018). Engineers and operators can accept a decision from their own project manager more easily than they accept one from the competing project manager. Double control is essential to ensure each firm of the quality of work performed by the partner (Fernandez et al., 2018)

\subsubsection{Organizational design in dyadic coopetition: separate and coopetitive projects teams}

One of the key questions in coopetition management is how to design the organizational structure of coopetitive projects (Le Roy et al., 2018; Le Roy \& Fernandez, 2015). In this context, prior literature highlights the development of two organizational designs, namely, the SPT and the CPT. According to Fernandez et al. (2018), the application of these organizational designs depends on the innovative character of the coopetitive project (incremental versus radical innovation), including features such as the risks, costs, and innovativeness of the coopetitive project (see Table 1).

The simplest organizational structure in dyadic coopetition is SPT (cf. Figure 1). This structure is used when coopetitors follow a vertical coopetition strategy, i.e., when they cooperate by splitting up the different stages of the value chain (Gernsheimer, Kanbach \& 
Gast, 2021). Each coopetitor is in charge of some value chain stages, while the other are executed by the others. In the satellite manufacturing industry, for instance, global and local firms should cooperate vertically to win calls for tenders in emerging markets (Fernandez, Le Roy \& Chiambaretto, 2018). The manufacturing process of the satellite is divided between the cooperating coopetitors. While the local firm develops the platform, i.e., the standard part of the satellite, the global firm develops the payload, which is the innovative part of the satellite.

In such SPTs, there is no common team for the project. Each coopetitor has its own project-related team. Coopetitors do not work together intensively. They are connected at the interfaces and share the basic knowledge that the other team needs to ensure the project's success. SPTs are relevant for low-cost, low-risk, and low-innovation projects. It permits strong knowledge protection by limiting sharing between coopetitors. The principle of separation is mainly used, and only the project manager at the "interface coordination" between the two separate teams needs to integrate the coopetition paradox.

Figure 1. The Separated Project Teams

(Source: Fernandez et al., 2018)

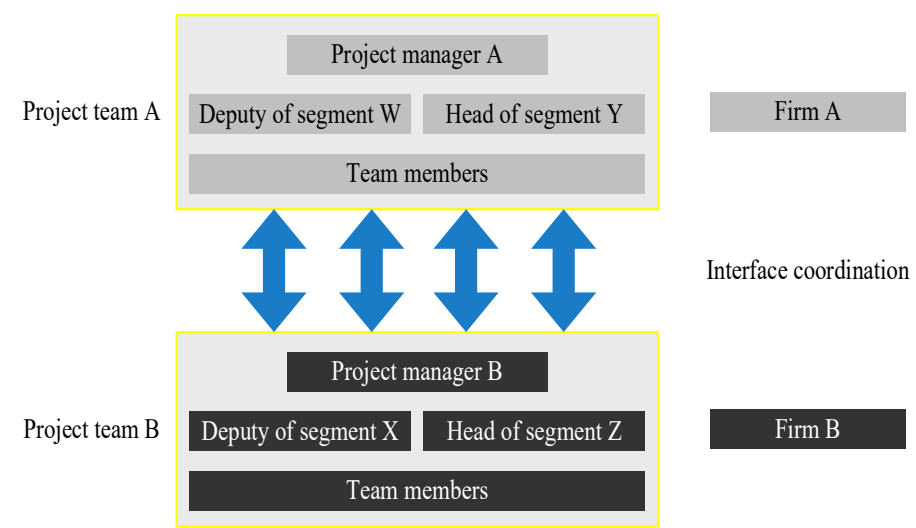

A more complex organizational design used in dyadic coopetition is the CPT (cf. Figure 2). This structure is used when coopetitors follow a horizontal coopetition strategy, i.e., when they collaborate at the same stage of the value chain. For instance, in the satellite manufacturing industry, two global firms should cooperate horizontally to win calls for tenders against other global competitors (Fernandez, Le Roy \& Chiambaretto, 2018). The 
satellite manufacturing is not divided between the cooperating coopetitors. Instead, the two global firms cooperate to jointly develop the platform and the payload.

The CPT is relevant for high-risk, high-cost, and high-innovation projects. Indeed, to be successful, those projects require intense sharing between coopetitors (Fernandez, Le Roy \& Chiambaretto, 2018). Coopetitors have to share their knowledge intensively and daily. A CPT involves employees of the two coopetitors who work together intensively every day in the same place (Le Roy \& Fernandez, 2015). This daily and intensive sharing permits the knowledge cross-fertilization and creation needed for radical innovation. Nevertheless, it generates uncertainty on undesired knowledge leakages which requires formal and informal knowledge protection mechanisms (Fernandez and Chiambaretto, 2016).

\section{Figure 2: The Coopetitive Project Team}

(Source: Le Roy and Fernandez, 2015)

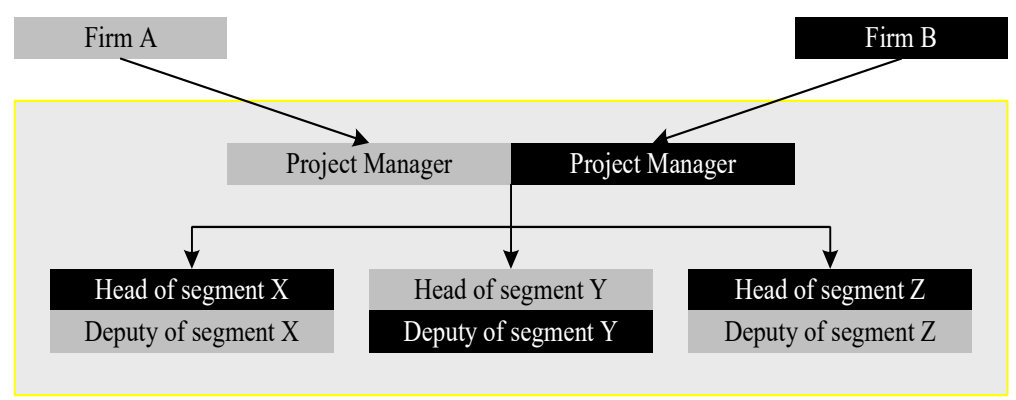

Inside CPTs, coopetitors implement co-management in a dual structure, i.e., an organizational structure in which all positions are doubled with one employee from each company. There is no hierarchical principle between the two companies' employees but rather a co-management to horizontally manage technological challenges and inevitable conflicts between co-owners. This co-management induces high coordination costs but also enables the sharing of knowledge. 
Table 1: Management of dyadic coopetition

(Source: authors)

\begin{tabular}{|c|c|c|}
\hline & SPT & CPT \\
\hline Characteristics of projects & \multicolumn{2}{|l|}{} \\
\hline Risks & Low & High \\
\hline Costs & Low & High \\
\hline Innovativeness & Low & High \\
\hline Coopetitive dilemma & \multicolumn{2}{|l|}{} \\
\hline Sharing & Low & High \\
\hline Protecting & High & Uncertain \\
\hline Management principles & \multicolumn{2}{|c|}{} \\
\hline Separation & High & High \\
\hline Integration & Low & High \\
\hline Co-management & Low & High \\
\hline
\end{tabular}

\subsection{Management of oligo-coopetition}

Previous research on coopetition has focused mainly on dyadic coopetition. However, coopetition is not only about dyadic relationships. Another form of coopetition that has developed actively in recent years is oligo-coopetition" which involves more than two but a limited number of coopetitors.

A higher number of coopetitors increases a priori coopetition's potential value creation. The more coopetitors there are, the more resources and skills that they can share and thus improve their costs and capacity for innovation (Yami \& Nemeh, 2014) and limit their monetary losses in case of failure (Czakon et al., 2020; Gnyawali \& Park, 2009; Schiavone \& Simoni, 2011).

However, oligo-coopetition also leads to higher uncertainty about each other's behavior. In a dyadic relationship involving only two partners, the opportunistically behaving partner is easier for each coopetitor to identify since it can only be the other partner. In oligocoopetition, however, it is less easy to identify opportunistically behaving partners, as there 
are multiple ones. This problem is all the more acute as the number of coopetitors increases. In this situation, tensions related to coopetition should also increase.

Therefore, the efficient management of oligo-coopetition is an important research question. Only a few past studies have focused on this question. Rouyre and Fernandez (2019) studied "coopetition between several competitors" in the Galileo project and showed that using CPTs is difficult. Indeed, the large number of coopetitors creates too much fear of sharing knowledge. Coopetitors solved this problem by using the client, i.e., the European Spatial Agency, as a third party to moderate their relationships. This third party organizes the tasks as a central network actor, and the coopetitors just share information and knowledge with him. This key role of a third party is confirmed by Planko, Chappin, Cramer, and Hekkert (2019), Bez and Chesbrough (2020) and Smiljic (2020). The inclusion of a noncompeting neutral third party seems to be an effective strategy to manage coopetitive projects involving several coopetitors.

Nevertheless, such a third party does not always exist in oligo-coopetition (Enberg, 2012). What happens when there is no third party? How do companies manage the tensions associated with oligo-coopetition when there is no third party? Which organizational designs are used for innovative projects in oligo-coopetition when there is no third-party? To the best of our knowledge, extant research does not answer these questions.

\subsection{Tentative analytical framework}

To develop a nuanced understanding of the management of projects done in oligo-coopetition, we developed a tentative analytical framework (Sinkovics, 2018; Bouncken \& Barwinski, 2020; Bouncken et al., 2021a; Bouncken et al. 2021b) based on existing research dedicated to the management of dyadic coopetition (see Table 1). Following these insights, we consider that the management of oligo-coopetition strategy depends on the characteristics of the coopetitive projects (see figure 3). 
In oligo-coopetition, the higher number of coopetitors increases the complexity of the collaboration and the risk of opportunism which is a challenging situation for the respective companies. Consequently, the level of cooperation should be low, and the coopetitive project should not succeed without the help of a neutral and moderating third party (Rouyre and Fernandez, 2019).

In the absence of such a third party, we assume that the situation should be different according to the characteristics of the coopetition project. For low innovative coopetition projects with low costs and low risks, coopetitors do not have to share too much of their knowledge (Fernandez, Le Roy \& Chiambaretto, 2018). They can limit cooperation to common work at the interface. Therefore, they can decrease the threat of unintended knowledge spillover. We can suppose that for this type of project, companies involved in oligo-coopetition may use an organizational design based on SPTs and the accompanying management principles.

Expected pattern 1: For low-risk, low-cost, and low-innovative coopetitive projects performed in oligo-coopetition without a moderating third party, coopetitors should implement a vertical coopetitive strategy based on SPT's organizational design and its accompanying management principles to ensure the project's success.

For high-risks, high-cost and highly innovative projects, coopetitors have to share their knowledge intensively (Fernandez, Le Roy \& Chiambaretto, 2018; Bez \& Chesbrough, 2020). This sharing increases the innovative capabilities but also the risk of plunder. In dyadic coopetition, companies adopt the organizational design of a CPT and the accompanying management principles (see table 1) to both share and protect their knowledge. This type of organizational design, however, seems difficult to implement in the situation of oligocoopetition (Rouyre and Fernandez, 2019). Indeed, the opportunism risk increases as the number of coopetitors increases. When there is a third party, to ensure the success of the 
project, each coopetitor shares its knowledge with the third party but not directly with the other coopetitors. A priori, in oligo-coopetition without a moderating third party, it seems complicated to successfully manage projects with high risks, high costs, and high innovativeness using an organizational design based on CPT.

Expected pattern 2: For high risk, high cost, and highly innovative coopetitive projects performed in oligo-coopetition without a moderating third party, coopetitors should not implement an organizational design based on CPTs and their accompanying management principles to ensure the project's success.

Figure 3: Tentative analytical framework

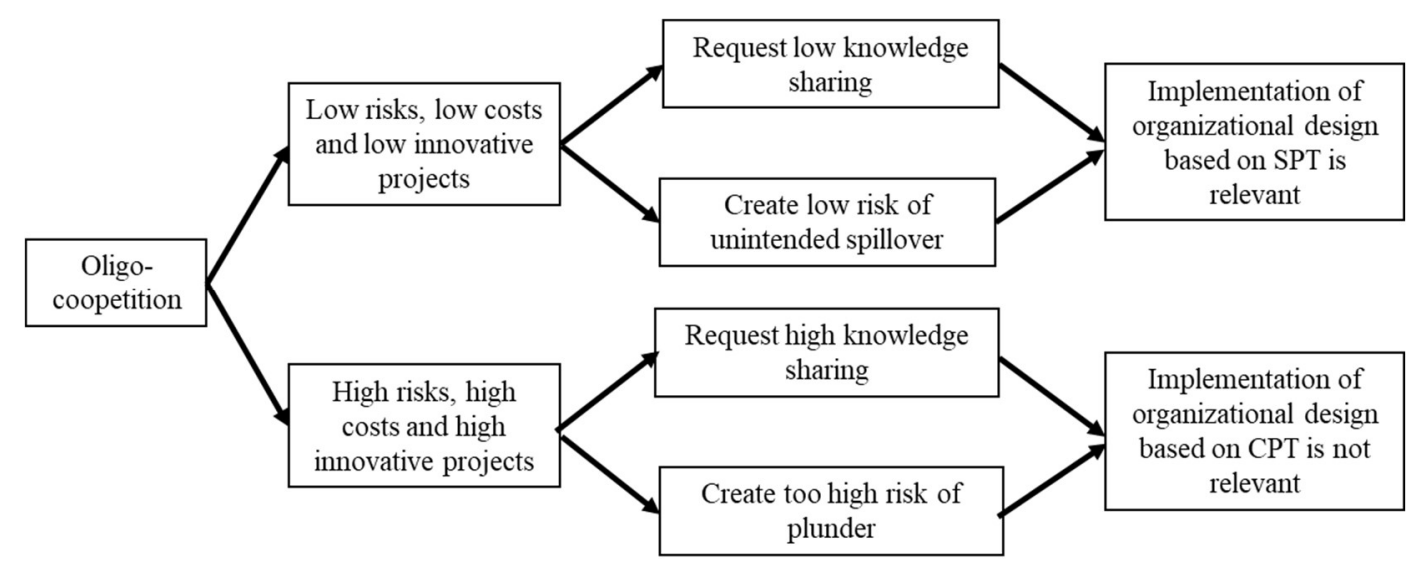

\section{METHOD}

\subsection{Research design}

We adopted a qualitative case study design to collect data and a flexible pattern matching approach (FPMA) to problematize and develop theoretical ideas (Bouncken et al., 2021; Sinkovics, 2018). We seek to understand the management principles and organizational designs of projects in oligo-coopetition. To explore the dynamic and paradoxical aspects of coopetition, a qualitative and explanatory case study design is recommended (Chiambaretto, Massé \& Mirc, 2019; Fernandez \& Chiambaretto, 2016; Gnyawali \& Park, 2011), as it facilitates an in-depth understanding of a particular phenomenon by analyzing it in detail in a limited context (Yin, 2009). 
We, therefore, employed an explorative research design by conducting a longitudinal case study of one of the major oil and gas exploration and production companies, enabling a holistic understanding of the studied phenomenon (Dumez, 2016; Eisenhardt, 1989; Yin, 2009). Furthermore, this approach allowed us to investigate and interpret changes over time (McLeod \& Thomson, 2012). This is important since coopetition is a complex and dynamic strategy, and previous research on coopetition highlighted that different organizational designs and managerial principles could be used by the same company depending on the cost, risk, and innovation requirements of the project (Fernandez, Le Roy \& Chiambaretto, 2018).

\subsection{Research context}

Total Group is a French private oil company among the four largest private international oil and gas companies in the world. It generated $€ 119704$ million in revenue in 2020. Total operates in 130 countries in all oil chain segments, from upstream (exploration, development, and production of oil and natural gas or LNG) to downstream (refining, distribution, trading, and shipping of crude oil and petroleum products). This study analyzes the company's OGEP projects. In particular, we examine the organizational design implemented in joint OGEP projects that involve several competitors' participation.

Since its creation in 1924, Total Group has competed with other major oil and gas companies (e.g., ExxonMobil, Shell, Chevron, BP, and ConocoPhillips) on its OGEP projects. OGEP activities have the particularity of being long in terms of time. The average duration of successful OGEP exploration projects is approximately twenty years, and the exploration phase lasts approximately ten years before a return on investment is secured. These projects are also costly, complex, and risky: an exploration campaign can cost from $€ 200$ million to $€ 50$ billion, and the probability of stopping a project because it is considered uneconomic is high. Therefore, coopetition is of particular interest to competitors in the oil industry (Gnyawali \& Park, 2011; Ritala \& Sainio, 2014). 


\subsection{Data collection and analysis}

The case study is based on the collection of primary and secondary data. The primary data provided a narrative summary of Total's OGEP projects from its initial creation in 1920 until today. To ensure the data's internal validity, each critical event or identified sharing modality was verified through a triangulation process with different sources (see Table 2).

Table 2 - Types and sources of data

\begin{tabular}{|c|c|}
\hline Type of data & Details \\
\hline \multirow[t]{4}{*}{ Interviews } & Number: Twenty people, including one with whom we conducted several interviews \\
\hline & Collection method: Semi-directive interviews conducted face-to-face or by telephone \\
\hline & $\begin{array}{l}\text { Average duration: } 50 \text { minutes, except for one person with whom several interviews } \\
\text { were conducted for a total duration of } 9 \text { hours }\end{array}$ \\
\hline & $\begin{array}{l}\text { Three levels of responsibility: } \\
\text { - Four interviews with senior executives at Total's parent company who are involved } \\
\text { in decisions to cooperate in exploration and production projects at the global level } \\
\text { - Seven interviews with specific asset managers who have a global vision and } \\
\text { influence on decisions at the project level with a partner in a geographical area } \\
\text { - Nine interviews with operational staff involved in exploration and production } \\
\text { projects with partners }\end{array}$ \\
\hline Observations & $\begin{array}{l}\text { Two days of immersion in a training course within Total concerning our research topic, } \\
\text { in this case, consortia with external partners including competitors }\end{array}$ \\
\hline \multirow{2}{*}{$\begin{array}{l}\text { Published books } \\
\text { and academic } \\
\text { articles }\end{array}$} & $\begin{array}{l}\text { Book published by the International Association of Petroleum Traders and written by } \\
\text { Walker in } 2020\end{array}$ \\
\hline & Book “The Petroleum Handbook,” published by Shell in 1986 \\
\hline Annual reports & Total's annual reports from 2002 to 2018 \\
\hline $\begin{array}{l}\text { Press articles and } \\
\text { Total database }\end{array}$ & $\begin{array}{l}\text { To deepen our knowledge of the elements resulting from interviews or secondary data: } \\
\text { - } \quad \text { Total's press articles published between } 2002 \text { and } 2018 \\
\text { - } \quad \text { Total's virtual database based on Total Group archives (available online) }\end{array}$ \\
\hline
\end{tabular}

To analyze our data, we employed the flexible (stepwise) pattern matching approach as proposed by Sinkovics (2018) and applied in recent strategy research (Bouncken \& Barwinski, 2020). We, thus, build our analysis on a tentative analytical framework (see section 2.4) specified a priori to provide guidance and focus. As such, this approach allows for a theory-driven research paradigm while at the same time letting new constructs, dimensions, and patterns emerge from the collected data (Sinkovics, 2018). As such, the theory-based analytical framework is advanced based on a practice-driven approach (Brooks \& King, 2014). 
To reduce the risk of bias, a narrative summary and the aforementioned three ways of collaborating with competitors were compiled before the research analysis grid was defined (Dumez, 2016). We then developed our analysis grid based on the variables presented in Table 1 and the tentative analytical framework in Figure 3 in three phases.

First, we characterized the observed projects in terms of the three identified ways of coopeting based on three characteristics known to influence coopetitive project design: (1) joint project costs, (2) risks, and (3) the degree of innovation. In the second phase, we characterized the organizational designs of the projects based on the distinction between SPTs and CPTs. In the third phase, we characterized the management principles based on the known coopetition principles: separation, co-management, and integration. In doing so, we observed differences in the projects' strategic and operating levels. Finally, to confirm the accuracy and adequacy of our data and interpretations (Lincoln and Guba, 1985), our interpretation of events was presented twice to a Total executive who confirmed it.

\section{RESULTS}

The results highlight three oligo-coopetition strategies: (1) "shareholder" coopetition, (2) "vertical" coopetition, and (3) "combined vertical and horizontal" coopetition. Total uses each of these coopetition strategies according to the characteristics of its different oil and gas production projects in terms of risks, costs, and innovativeness.

\subsection{Shareholder coopetition}

From its founding, Total ${ }^{1}$ accessed oil and gas using "shareholder" coopetition. After its creation, Total sought to produce its oil, but the company was often unable to access the land containing significant oil reservoirs, either in France or abroad. French soil contained little $\mathrm{oil}^{2}$, and the major oil companies of that time ${ }^{3}$ already held all the foreign territories known

1 The firm at this time was called the Compagnie Française des Pétroles (CFP), literally the "French petroleum company."

2 Oil exploration on French soil between 1920 and 1935 revealed that it was poor in oil, with the exception of a few small discoveries and an important natural gas field that was technically very difficult to develop. 
for their oil reservoirs. During one of our interviews, a senior manager explained, "There was no more space to conquer; the territory was already partly divided [by the major oil companies]." Since that time and until today, Total has bought equity stakes into existing OGEP projects belonging to its competitors. For instance, in 2018 , a total of $8.44 \%$ of the giant Johan Sverdrup oil development was acquired in Norway ${ }^{4}$.

The specific feature of this oligo-coopetition strategy with the major oil companies is that all but one of the coopetitors remain only shareholders, contributing financially to coopetitively owning a share of the potential oil and gas production. They are not involved in shared operating activities or developing joint technologies.

Figure 4 - The organizational design of "shareholder" coopetition
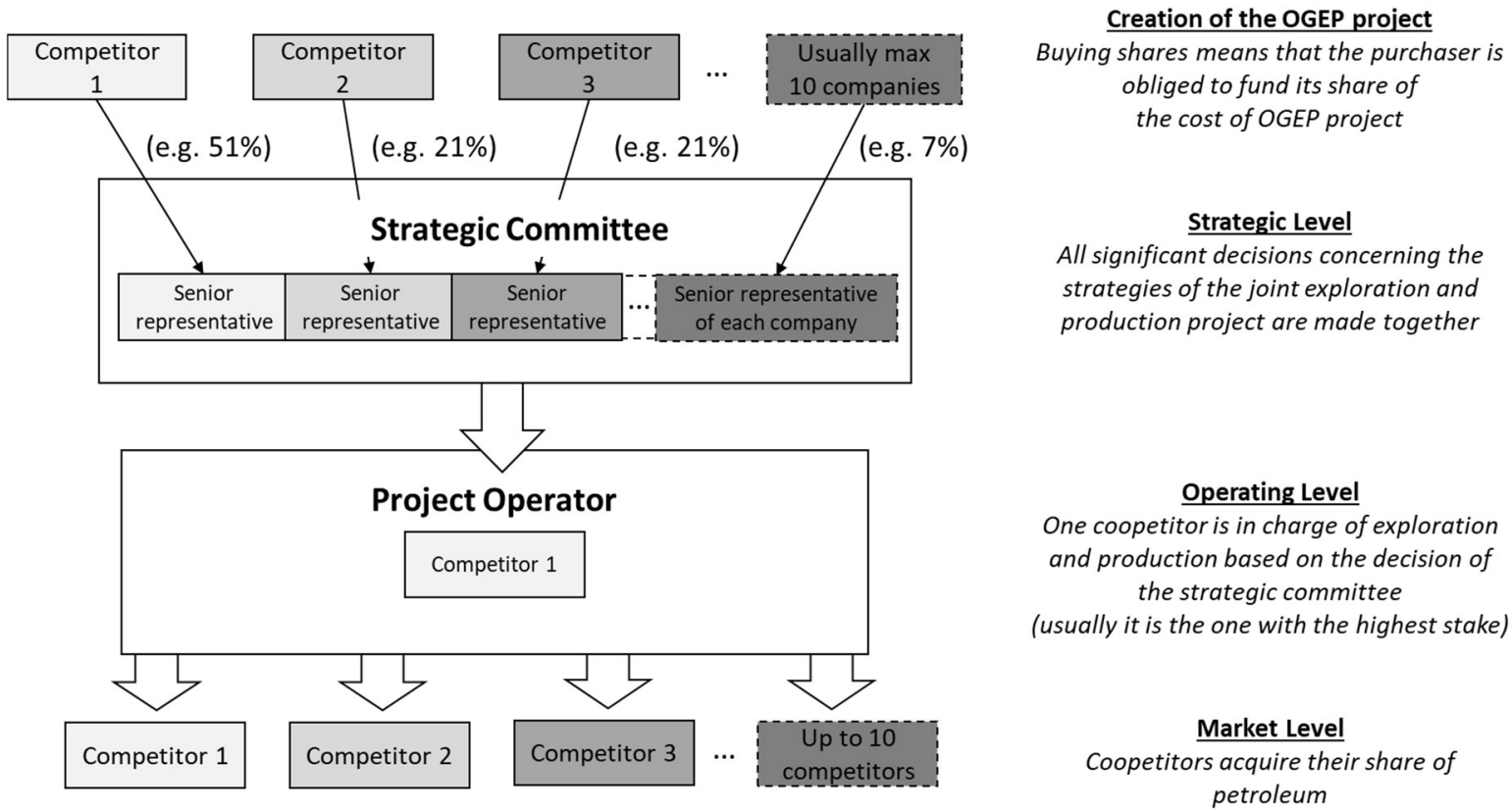

Regarding the management of this coopetition strategy, we observe that coopetitors put in place an organizational design consisting of three layers: a strategic level, an operational level, and a market level (cf. Figure 4). At the strategic level, all companies have a senior representative, i.e., the CEOs or their substitutes. Together, these representatives form the socalled strategic committee. Committee members are in charge of making all significant 
decisions concerning the strategies of the joint exploration and production project. Although all coopetitors co-finance the project, they compete against each other over their individual percentages in the project and the role of the so-called project operator. Each member keeps in mind that they have to collaborate on the project while they are simultaneously fierce competitors on other projects.

At the operational level, only one coopetitor is appointed to the project operator in charge of implementing the exploration and production project. This choice of having only one of the coopetitors as an operator is intentional. As costs are divided based on the coopetitors' individual shares, they usually give the lead to the company with the largest share. In doing so, coopetitors protect themselves from resource misuse, as the coopetitor with the largest share is the one that would lose the most in case of a waste of resources.

\subsection{Vertical coopetition}

In addition to "shareholder" coopetition, Total is involved in projects based on vertical coopetition. This second coopetition strategy started in the 1950s and is still used today for some projects. Until the 1950 s, political and historical issues related to concession contracts and the existence of settlements fixed the distribution of geographical areas containing oil. At the end of the 1950s, international companies became aware of the need to diversify their oil supply. Indeed, the majority of companies noted that increasing the number of OGEP projects helped to combat the decline in production in their countries of origin and reduce their dependence on the Organization of the Petroleum Exporting Countries (OPEC).

The colonies' independence came at an auspicious time; competition was partly freed from political and historical constraints. Access to geographical territories was given to the most advantageous companies for the country, i.e., companies capable of maximizing exploitation at the lowest cost. Intensified competition started to emerge in these geographical areas. 
Between its creation and this specific time of intense new competition, Total developed a high level of advanced technology that none of the other major oil companies could produce (i.e., corrosion-resistant steel). As a result, Total became a major market participant and competed with the largest oil companies in new tenders. On several occasions, Total even won some tenders alone.

However, technological competition was so strong and evolved so fast that large R\&D investments were not enough to maintain technological superiority. The winning strategy to secure tenders thus consisted of making the most attractive offer to states by collaborating with competitors holding complementary technologies. Joint offers thus became far superior in terms of technology to the offers that Total or its competitors could make alone.

Collaboration was considered mandatory for optimizing the exploration and exploitation of large and complex projects. In this regard, one interviewed manager explained, "Total still has a few field policies where you are on your own. Another specific case is that we start at $100 \%$ Total. The Comex [says] 'OK, we can go.' However, then, during exploration, we get additional information, and we say, 'Oh, that is too big of a challenge,' [and so we look for another international group that would like to participate]." Conversely, even if Total is defeated in a tender, the winner of the tender may propose that Total joins the project, provided it agrees to combine its technology with that of the competitor.

The behavior of states accentuated the development of this cooperative behavior between competitors. Given the increasing demand for tenders, states became aware of the advantage that they had in having access to geographical areas. They even modified contracts to offload the risk of project failure. As a result of these contract changes, OGEP projects became riskier for companies since the risk of failure was no longer shared with the host country. The increasing level of risk also encouraged the use of competitors' technologies if such technologies were more advanced. 
In this scenario of coopetition for technology combination, coopetitors put in place a similar organizational design to that used in coopetition for resource access, with strategic, operational, and market levels. At the strategic level, in the case of a successful bid, all coopetitors are still part of the strategic committee and co-finance the joint project while benefiting from the jointly exploited and produced oil (cf. Figure 5).

However, the design of the operational level differs slightly. At this level, the company with the largest share or the most technically advanced company becomes the project operator leading the operating activities. Since the project operator may not necessarily possess all the required technologies for the joint OGEP project, support operators are occasionally appointed to carry out incidental technological tasks related to the joint project. Put differently, the support operator plugs its technology into the process managed by the project operator but does not share the technology. The project operator thus delegates specific tasks to coopetitors depending on their technological skills and capabilities, leading to a combination of technologies being held individually by coopetitors.

For example, some operators in Brazil, the Gulf of Mexico, Angola, or the Eastern Mediterranean are currently delegating the underground data analysis to Total, which has advanced imaging algorithms and one of the world's most powerful computers (the computer called Pangea III is considered in 2019 as the number 1 among supercomputers in the oil and gas sector, and number 11 globally). Indeed, delegating to Total can save time and cost to operators operating in a complex environment, such as when the oil is trapped under salt. Kevin McLachlan, the company's senior vice president for exploration, considers that "tens of millions of dollars of savings would be made on the oil wells as a direct result of obtaining better images" and "what used to take a week, now takes us a day to process [thanks to this supercomputer]." 
In these cases, as Total is not appointed as the project operator of a particular joint OGEP project, the respective project operator appoints the company as a support operator, entrusting Total with the task of modeling calculations without sharing its technology. Thus, the calculation modeling was performed internally, and only the results necessary for the joint OGEP project were shared. Total technology is therefore protected from unintended acquisition.

\section{Figure 5 - The organizational design for vertical coopetition}
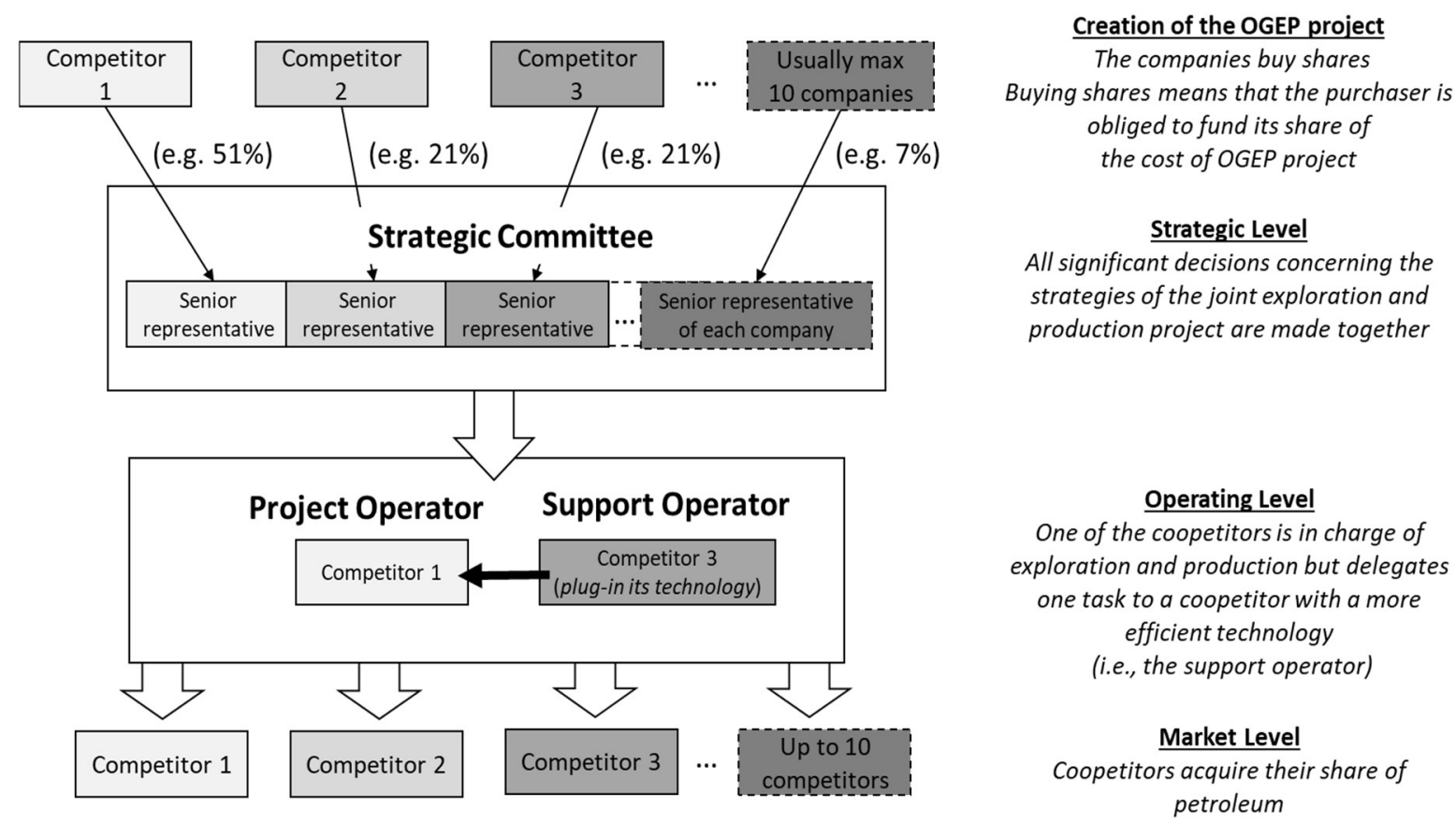

Being an assigned project operator or support operator is a source of competition as well as competitive advantage; indeed, de facto, coopetitors are still competing over these positions. If a coopetitor's technology is chosen for a joint OGEP project, this means that the involved competitors validate the superiority of that particular technology. In concrete terms, when Total succeeds in becoming the project operator or in having its technologies used as a support operator in successful joint OGEP projects, this empirically certifies its effectiveness and affirms its superiority in this field. One of the interviewed directors stated, "In this profession, being an operator is better than not being an operator. It is a technological showcase [that] allows us to develop and enhance our skills." 
Even if the delimitation between the project operator and support operator is well defined and thus reduces the sharing tension, the sharing tensions are still there. One interview from the support team explained having trouble obtaining the data from the operating employee of the project operator team. The operating employees ask him to reveal the advanced imaging algorithms in exchange for the data, even if it was not included in the contract. In the end, these reluctant operating employees accept the situation, but there is some time waste and heated discussion to manage.

\subsection{Combined vertical and horizontal coopetition}

From the 1970s, a third strategy of coopetition, which we named "combined vertical and horizontal" coopetition, started to be used in addition to the two first strategies. At this time, the oil production market became more open, and competition for geographical areas potentially containing oil grew fiercer. Indeed, smaller national oil companies were beginning to master the technologies needed to exploit their resource fields at a lower cost. Consequently, these companies gradually crowded out the major oil companies from the most profitable oil exploration fields. As a result, between 2004 and 2013, oil production from the five major oil companies (ExxonMobil, Shell, BP, Chevron, and Total) decreased by $25 \%$ to the advantage of smaller national oil companies. At that time, Total and the other major oil companies feared that these national companies would increasingly be interested in exploiting deposits outside their territories and would then compete directly with them in tenders.

Facing this threat of national oil companies catching up with them in terms of technology, Total, and the primary reservoir groups felt an urgent need to differentiate themselves from national companies. In this situation, one possible strategy would have been to continue to combine existing technologies across the major oil companies. Total and the other major oil companies, however, decided to implement and pursue a strategy of pioneering new markets requiring new technology development. Indeed, the OGEP market for oil in hard-to-reach 
areas was challenging to access. Such areas have never been explored because of the complexity of oil exploration and the lack of technology to overcome this complexity (e.g., offshore or very deep-sea exploration).

The general decline in oil production reinforced this new strategy as, consequently, states sought to increase their exploitation of geographical areas that were difficult to access. For these territories, only the five major oil companies had the necessary skills and capacity to potentially develop a specific technology that would allow access.

Despite their existing skills and technologies and regardless of the outcome of the call for tenders, the major oil companies could not undertake these projects in hard-to-reach areas alone. These projects were de facto more complexes, more expensive, longer, and more technology intensive than existing projects. For instance, they were twenty times more expensive and non-equity financeable, with a high probability of failure and an investment lock-in period of approximately 20 years.

It was thus clear that Total could not undertake these projects alone. Banks refused to make specific loans for these projects, which were characterized by a failure rate of two-thirds. A Total senior executive interviewed in 2014 stressed this specific need for cooperation with competitors, particularly for deep-water projects: "It is tough to support this exploration phase, so we go in together. Furthermore, what is even heavier is the appreciation and especially the development part. The aim is to develop petroleum gas in the deep sea. Here, the down payment is huge: we cannot make it alone." Another senior executive confirmed that working with a competitor could diversify risk: "The idea is still to reduce risk or spread our holdings over more companies and then manage a portfolio of positions in a more balanced way so that what is going wrong is offset by what is going well." Therefore, during this period, Total needed to work with its competitors to co-finance projects and share risks, as competitors were the only partners willing to engage in these costly and risky projects. 
Their engagement in these hard-to-reach areas helped protect the major oil companies from encroachment by smaller national companies, which had neither R\&D nor the desire to manage such complex projects. Nevertheless, at the same time, the stakes and the costs of these projects were enormous and, above all, marked by the uncertainty of succeeding in developing the appropriate technology to manage these challenging contexts.

\title{
Figure 6 - The organizational design of combined vertical and horizontal coopetition
}

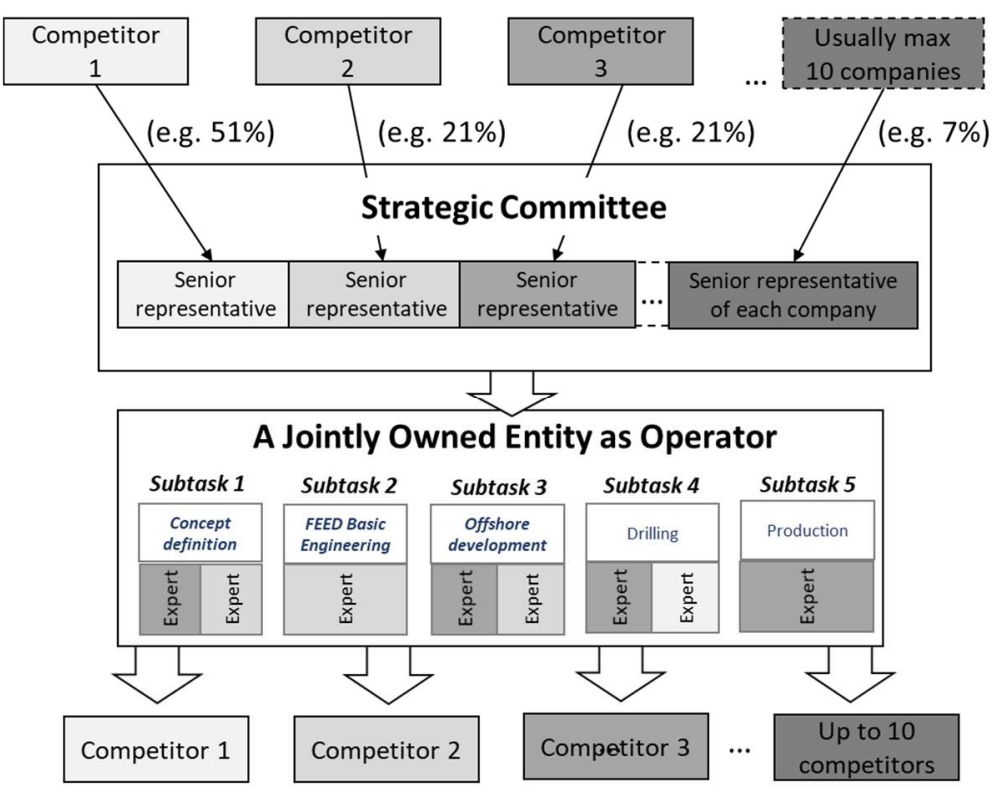

\author{
Creation of the OGEP project \\ The companies buy shares; \\ Buying shares means that the purchaser is \\ obliged to fund its share of \\ the cost of OGEP project \\ Strategic Level \\ All significant decisions concerning the \\ strategies of the joint exploration and \\ production project are made together

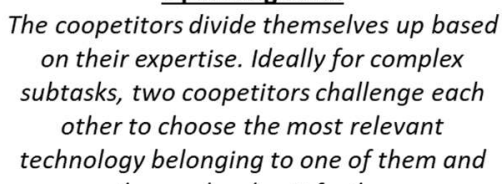 \\ petroleum
}

This need to independently develop the required technology to find oil in these difficult areas, and the related uncertainty led to the emergence of a specific organizational design permitting technology co-development. While this design does not involve significant changes at the strategic level, it is characterized by more control from all coopetitors and increased knowledge sharing among them at the operational level. The general idea of this organizational design is to allow coopetitors' most qualified experts, regardless of their company of origin, to control and supervise the joint OGEP project's operations (cf. Figure 6). Hence, the strategic committee may appoint as an operator a jointly owned entity in which each party is a shareholder and/or member on the entity's corporate board of directors. 
Further, if the parties can staff the entity with secondees, then each party that sends secondees to the incorporated entity can have one or more of its own employees on the inside of the operating company. One of the senior executives thus highlighted the importance of not being alone in operation: "When you have only the opinion of your own experts, you only have one opinion. When we are in a joint venture, there is a discussion, and often, what has been said by three companies, at the end of the day, it is more intelligent even if the discussion is lively and we scream, and we are not happy with the partners. [...] There is the opinion of Chevron in addition to the opinion of Total and then the opinion of Conoco in addition to the opinion of Chevron., and that it helps to put things into perspective, we do not all have the same ideas, we get criticized [...], it is still a very civilized thing where everyone wins. The discussion must take things further." ${ }^{\prime 6} \mathrm{~A}$ key point for the success of this organizational design is the selection of the coopetitors involved in the operational subtasks. Not all coopetitors are involved. An involved coopetitor can be in charge of the subtasks alone or can be joined by one or more rarely two coopetitors with strong skills in the area. If a coopetitor has no related skills, it cannot help choose and improve the technology to use or the process to follow on the sub-task.

The selection of companies involved in the shared subtask is very challenging. The companies that truly master the technology want to limit the subgroup only to companies advanced enough in close technology to create something new together. However, the other low-tech companies, especially those coming from emergent companies, also want to be involved and learn from their more advanced coopetitor. This situation creates high tension at the strategic level to decide whom to be involved in the subgroup. The principle is the following: only companies that can prove high skills in the subtask should be admitted. The 
implementation of this principle is always high of tension, but it is respected because this is the condition of sharing and improving technology.

Thanks to this coopetition strategy and this specific organizational design, coopetitors involved in high-tech subgroups can optimize all decisions and, above all, choose and develop together the technologies necessary for the success of their joint OGEP projects. In particular, the implemented organizational design offers a way to leverage the technology and process to exploit and produce oil in hard-to-reach areas, supported by the sharing of expertise and knowledge of all involved coopetitors.

For example, Total had a useful technology for conceptualizing and evaluating oil and gas potential, but it could not use this technology for shale gas. By sharing its technology with a competitor that was more familiar with current shale gas potential assessment technologies, Total could leverage its technology for the specific situation. This leveraged technology was used in the exploration of gas, and gas was successfully found.

The key point is that the technology in a chosen subgroup gives a real advantage to the technology owner. Indeed, first, all technologies used in a project are co-financed by all coopetitors. Second, by openly sharing the technology with a coopetitor with expertise in the topic, a firm obtains valuable insight into how to improve it. Paradoxically, one of our interviewees argued that even if its technology is not chosen, the company has a strong interest in sharing it in sub-tasks composed of experts, as other coopetitors have to explain why the technology is not chosen or is weaker than the chosen technology. This information offers critical feedback on how to improve the technology internally.

\section{DISCUSSION}

\subsection{Three strategies of oligo-coopetition}

The results show three strategies of oligo-coopetition through which the observed companies seek to secure their share in the future production of oil and gas: (1) "shareholder" 
coopetition, (2) "vertical" coopetition, and (3) "combined vertical and horizontal" coopetition. In the first strategy, i.e., "shareholder" coopetition, coopetitors do not seek technological cooperation because the costs and risks of the joint project are relatively low, and there is no need to engage in cooperative activities to jointly develop technological innovations. This strategy has not been highlighted in prior research on dyadic coopetition and seems to be specific to the oligo-coopetition context.

In the second strategy, i.e., "vertical" coopetition, coopetition is initiated to allow coopetitors to plug in their best technologies according to their efficiency. Coopetitors individually pool their technologies without being involved in the co-development of technologies. This strategy has already been observed in dyadic coopetition situations for joint projects characterized by low innovativeness and average project costs and risks (Estrada, Faems \& de Faria, 2016; Fernandez, Le Roy \& Chiambaretto, 2018). Our research advances this prior insight by highlighting the existence of this strategy in situations of oligocoopetition.

In the third strategy, i.e., "combined vertical and horizontal" coopetition, coopetition is implemented to explore new and difficult areas with oil or gas potential, which requires competitors to cooperatively develop a relevant technology for extreme and unique conditions. For the less complex tasks, coopetitors plug in vertically their technologies as in the second oligo-coopetition strategy. But for the complex tasks requiring new technologies, competitors choose a particular technology of one coopetitor and horizontally co-develop it further.

This strategy of horizontal technology co-development has been identified in dyadic coopetition concerning projects with high innovativeness, high costs, and high risks (Fernandez, Le Roy \& Chiambaretto, 2018). Our research extends this knowledge from dyadic to oligo-coopetition scenarios. Oligo-coopetition as dyadic coopetition enlarges 
technological diversity (Quintana-Garcia \& Benavides-Velasco, 2004), improves innovation capacity (Ritala, 2012), and expands knowledge generation and diffusion among coopetitors (Ritala \& Hurmelinna-Laukkanen, 2009).

\subsection{Three different organizational designs and the accompanying management principles}

Our results highlight the use of different organizational designs and accompanying management principles in oligo-coopetition when a neutral and moderating third-party does not exist. For the three coopetition strategies, we find a clear distinction between two management levels; namely, the strategic and operational levels (cf. Table 2). This distinction between the strategic level and the operational level has already been highlighted in the context of dyadic coopetition (Le Roy and Fernandez, 2015; Fernandez, Le Roy \& Chiambaretto, 2018); our research, however, extends prior knowledge by focusing on the specific case of oligo-coopetition. In particular, we find that the projects' organizational designs and the related management principles are quite similar at the strategic level, while they are different at the operational level.

At the strategic level, coopetitors use the separation, co-management, and integration principles for all coopetitive projects. The separation principle is used for creating a strategic firewall between the cooperative project and the other projects of each coopetitor. Once this separation is secured, coopetitors apply the principles of co-management and integration. Within the strategic committee, coopetitors' CEOs practice co-management to control and supervise the joint project. Therefore, they are confronted with the need to individually integrate the coopetition paradox at the individual level to successfully handle the coopetitive relationship with the leaders of their competitor firms.

The application of the three management principles simultaneously is possible at the strategic level because there is only a limited risk of unintended operational knowledge 
transfer. At the operational level, however, this application is more challenging, as, by definition, operational knowledge is located at this level. At this level, the separation principle is implemented for three coopetition strategies. There is full separation between the joint project's operational activities and the other operational activities of each coopetitor.

For the co-management and integration principles, there are differences. In "shareholder" coopetition, no co-management and integration are needed at the operational level. Cooperation is limited to the joint financing and risk-sharing of projects. Coopetitors decide to keep the management of the process of joint oil exploration and production - and thus its control and supervision - in the hands of only one member company.

In "vertical" coopetition, similarly, no co-management and integration are needed at the operational level. Some efficient coopetitors plug their technologies into the project. The management, control, and supervision of the project are still in the hands of the appointed project operator. The support operator has no controlling power. The project and support operators performed specific tasks separately without any technology sharing or codevelopment. Only information on individual operations' results is shared, and no operator has access to the others' knowledge.

In "combined vertical and horizontal" coopetition, co-management and integration principles are needed at the operational level. At this level, co-management is implemented for the most complex sub-tasks. In this setting, there is no hierarchy between coopetitors, but continuous exchanges between experts allow problems to be solved and new technologies to be developed. They work together daily in horizontal relationships, presenting numerous opportunities to share their technologies, expertise, and knowledge. Co-management is, therefore, a critical factor in enabling the creation of the new technologies and knowledge required for a project. Operators also faced the need to integrate the coopetition paradox at the individual level. The more cooperative and open coopetitors there are, the more innovative the 
projects that can be developed. However, at the same time, they must be able to protect the company's knowledge from unintended spillover.

Table 3 -Organizational designs and management principles for oligo-coopetition

\begin{tabular}{|c|c|c|c|}
\hline & $\begin{array}{l}\text { Shareholder } \\
\text { coopetition }\end{array}$ & Vertical coopetition & $\begin{array}{l}\text { Vertical and horizontal } \\
\text { coopetition }\end{array}$ \\
\hline \multicolumn{4}{|c|}{ Characteristics of projects } \\
\hline Objective & \multicolumn{3}{|c|}{ Access to oil slicks } \\
\hline Innovativeness & No & Medium & Very High \\
\hline Costs & Low & Medium & Very high \\
\hline Risk & Low & Medium & Very high \\
\hline \multicolumn{4}{|c|}{ Coopetitive dilemma } \\
\hline $\begin{array}{l}\text { Technology } \\
\text { sharing }\end{array}$ & No & Low & Very strong \\
\hline $\begin{array}{l}\text { Technology } \\
\text { protection }\end{array}$ & Very strong & Strong & Uncertainty \\
\hline \multicolumn{4}{|c|}{ Organizational design of projects } \\
\hline Strategic level & \multicolumn{3}{|c|}{ Strategic committee composed of all member-companies' CEOs } \\
\hline Operational level & $\begin{array}{c}\text { One member-company's } \\
\text { expert appointed as sole } \\
\text { project operator }\end{array}$ & $\begin{array}{l}\text { One member-company's } \\
\text { expert appointed as sole } \\
\text { project operator who is } \\
\text { occasionally helped by } \\
\text { support operators }\end{array}$ & $\begin{array}{c}\text { Member-companies' experts } \\
\text { appointed as sub-tasks } \\
\text { operators based on their } \\
\text { expertise }\end{array}$ \\
\hline \multirow{2}{*}{\multicolumn{4}{|c|}{$\begin{array}{l}\text { Management principles } \\
\text { Strategic level }\end{array}$}} \\
\hline & & & \\
\hline Separation & Strong & Strong & Strong \\
\hline Co-management & Strong & Strong & Strong \\
\hline Integration & Strong & Strong & Strong \\
\hline \multicolumn{4}{|c|}{ Management principles } \\
\hline Separation & Very strong & Strong & Strong \\
\hline Co-management & No & Low & Strong \\
\hline Integration & No & Low & Strong \\
\hline
\end{tabular}

The three principles of coopetition management, i.e., separation, integration and comanagement, have yet been highlighted in past research dedicated to dyadic coopetition (Fernandez, Le Roy \& Gnyawali, 2014; Le Roy and Fernandez, 2015; Fernandez, Le Roy \& Chiambaretto, 2018). Our research extends this knowledge from dyadic to oligo-coopetition strategies. In particular, we find how each oligo-coopetition strategy combines differently the 
three principles of coopetition management according to the costs, risks, and innovativeness of the project.

\subsection{SPTs or CPTs for oligo-coopetition}

Past research has highlighted two organizational designs for dyadic coopetition: SPTs for low cost, low risk, and low innovative projects or CPTs for high cost, high risk, and highly innovative projects (Le Roy and Fernandez, 2015; Fernandez, Le Roy \& Chiambaretto, 2018). For oligo-coopetition, CPTs seem very difficult to implement (Rouyre and Fernandez, 2019). Indeed, increasing the number of coopetitors also increases opportunism risks. Intense cooperation cannot be developed, and the project has no chance of being successful. To ensure the project's success, a third party seems necessary to organize the project in SPTs and ensure knowledge sharing by its mediation. Coopetitors do not share their knowledge directly in a CPT but share their knowledge through the moderating help of the third party who acts as a broker (Rouyre and Fernandez, 2019).

Our research provides several new insights. For the first coopetition strategy, i.e., shareholder coopetition, we reveal that the organizational design is neither based on SPTs nor CPT. Indeed, one sole operator is involved in the oil and gas production. There is thus coopetition at the strategic level but not at the operational level. Operations are done as usual in an integrated company, without interactions with the coopetitors.

Therefore, our empirical results do not fully confirm the expected pattern 1 for the first coopetition strategy, leading to the following observed pattern:

Observed pattern 1: For low-risk, low-cost, and non-innovative coopetitive projects performed in oligo-coopetition without a moderating external third party, coopetitors implement at the operational level an organizational design based on one sole operator and its accompanying management principles to ensure the project's success. 
For the second coopetition strategy, i.e., vertical coopetition, the organizational design is based on the SPTs principles. These projects are characterized by medium cost, medium risk, and medium innovativeness. The separation is very strong, and coopetitors only interact at the interfaces. Knowledge sharing is low. To ensure the project's coordination, as there is no moderating external third party, one of the coopetitors becomes the internal operational third party. This coopetitor is chosen because it is recognized as the one with the greatest stake in the project and thus the most to lose in case of a failure. The coopetitor behaves as a neutral operator driven only by the success of the project. This arrangement is relevant because there is low knowledge sharing among coopetitors. It is easy for coopetitors to protect their operational knowledge.

Therefore, our results empirically confirmed the expected pattern 1 for the second coopetition strategy, leading to the following observed pattern:

Observed pattern 2: For medium-risk, medium-cost, and medium-innovative coopetitive projects performed in oligo-coopetition without a moderating external third party, coopetitors implement at the operational level an organizational design based on SPTs and its accompanying management principles to ensure the project's success.

In vertical and horizontal coopetition which aims to enable technology co-development, sharing is necessary for the most complex tasks. In this case, coopetitors first follow the SPTs principles for less complex tasks. The project is separated into sub-tasks dedicated to one coopetitor, and there is only interaction at the interfaces between the sub-tasks. However, this separation is not possible for all sub-tasks because none of the coopetitors can develop the needed technology alone. Therefore, coopetitors have to create subgroups for these high technology sub-tasks.

These subgroups include a limited number of coopetitors, usually two and no more than three. Only coopetitors with expertise in the specific area are involved in the selective 
subtasks dedicated to the development of this technology for the project. In doing so, knowledge sharing is permitted in the sub-task, and the exclusion of coopetitors without expertise offers protection against technology plunders by opportunist coopetitors. Of course, these sub-tasks' delimitation is full of tensions because most advanced coopetitors want to limit the number of coopetitors to companies with high skill. Unless less advanced coopetitors want to be involved to learn. These tensions are managed at the strategic level, at which companies must prove to others that they master the involved technology.

We thus find the following third observed pattern:

Observed pattern 3: For high-risk, high-cost, and highly innovative coopetitive projects performed in oligo-coopetition without a moderating third party, coopetitors implement at the operational level an organizational design based on SPTs dedicated to low complex subtasks; however, for sub-tasks requiring high innovation, coopetitors implement a suborganizational design based on CPT and its accompanying management principles.

This result is new in the coopetition literature and contradicts the idea that oligocoopetition for projects with high risk, high costs, and high innovativeness cannot be managed without a moderating third-party (Rouyre \& Fernandez, 2019). Therefore, we did not empirically confirm the expected pattern 2 . Instead, we find that despite the absence of a moderating third-party, companies in oligo-coopetition can organize themselves to jointly develop projects with high risk, high cost, and high innovativeness. However, the insights of past research remain valid: it is challenging to intensively share knowledge using CPT as the number of coopetitors increases (Rouyre \& Fernandez, 2019). Our results show that coopetitors can outdo this difficulty by using SPTs for low complex tasks and by recreating sub-CPT between a few selected coopetitors in global projects.

Furthermore, we show that once this kind of sub-CPT is designed, each included coopetitor aims to have its internal technology adopted for the project. Coopetitors in sub-CPTs show a 
strong interest in having their technology, expertise, and knowledge adopted within the subtask, as this means that the company's technology is considered the best by the entire profession, leading to a reputation effect. Hence, they proactively seek to share their technology, expertise, and knowledge as part of the joint project to be chosen again as a partner in tender projects. The ability to implement this counter-intuitive strategy, consisting of seeking to impose technology in oligo-coopetition and, at the same time, proactively share it with coopetitors, is an essential factor for a company's success. To our knowledge, this is the first time that this strategy has been highlighted in the literature on coopetition.

To sum up, the SPTs and CPT organizational designs have yet been highlighted in past research on dyadic coopetition (Fernandez, Le Roy \& Gnyawali, 2014; Le Roy and Fernandez, 2015; Fernandez, Le Roy \& Chiambaretto, 2018). Our research highlights their presence and their relevance in oligo-coopetition strategies. We find here how each oligocoopetition strategy uses SPTs and CPT according to the characteristics of coopetitive projects (cf. figure 7).

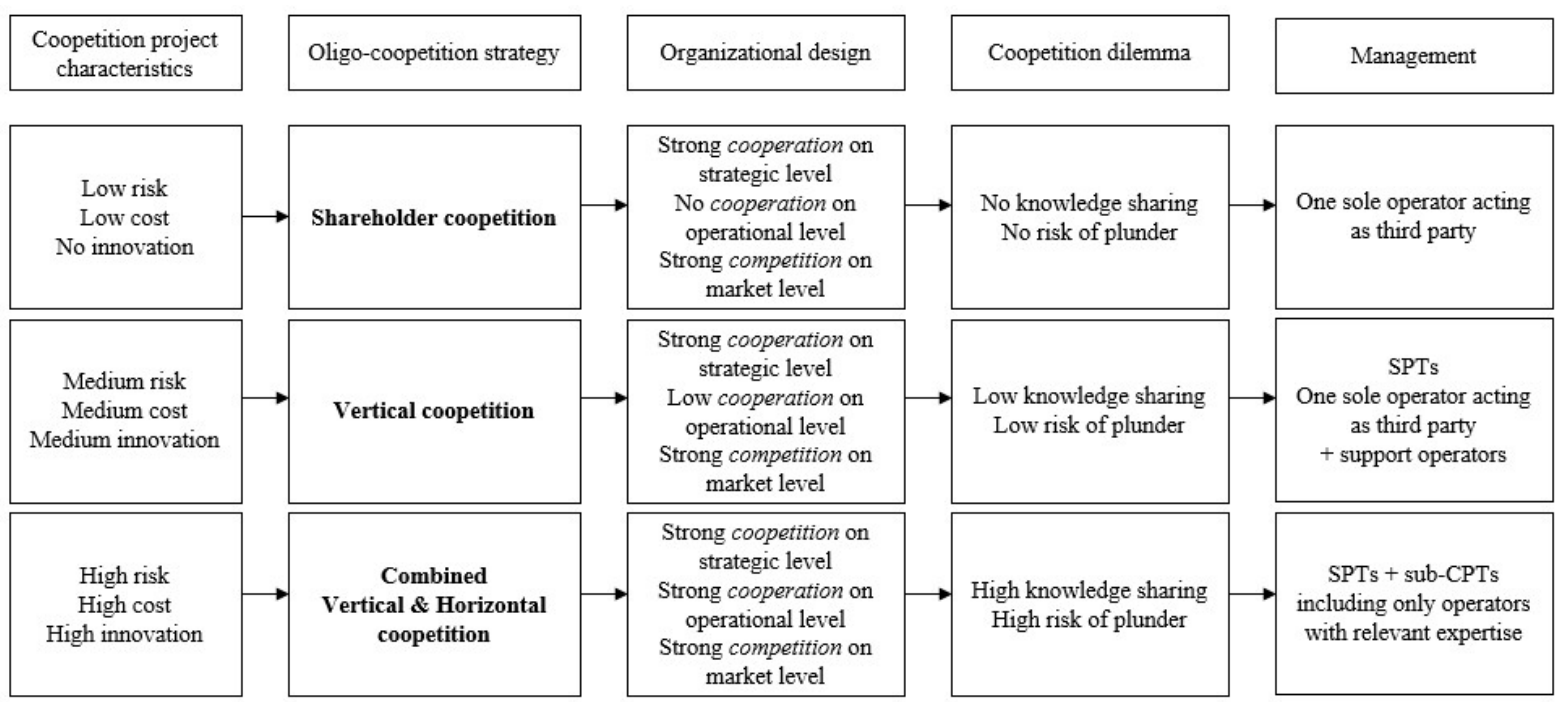

Figure 7 - Management of oligo-coopetition without a moderating third party 


\section{CONCLUSION}

This research sought to understand the organizational design and management of oligocoopetition when there is no moderating external third party. Using and further developing the flexible pattern matching approach (Sinkovics, 2018; Bouncken \& Barwinski, 2020; Bouncken et al., 2021a; Bouncken et al. 2021b), we built a theoretical framework based on past research on the management of dyadic coopetition and used this framework to conduct a case study analyzing projects in oligo-coopetition as well as their organizational design and management principles.

We identified three oligo-coopetition strategies and three associated organizational designs. First, with "shareholder" coopetition for low-risk, low-cost, and non-innovative coopetitive projects, coopetition exists on the strategic level while operational tasks are overseen by one single company, without knowledge sharing. Second, with "vertical" coopetition for mediumrisk, medium-cost, and medium-innovative coopetitive projects, the organizational design based on SPTs and its accompanying management principles enables coopetitors to limit knowledge sharing and permit its protection. Finally, with "combined vertical and horizontal" coopetition for high-risk, high-cost, and highly innovative projects, low complex sub-tasks are done in SPTs while highly innovative sub-tasks are done in CPTs. These results reveal the specificity of oligo-coopetition and the need for dedicated research.

\subsection{Theoretical contributions}

Our research contributes to the coopetition literature in several ways. First, it contributes to knowledge on coopetition by highlighting three oligo-coopetition strategies: "shareholder" coopetition, "vertical" coopetition, and "combined vertical and horizontal" coopetition. As such, we add to the discussion on the management of coopetitive projects on different stages of the value chain (e.g., Chiambaretto \& Dumez, 2016), including vertical (e.g., Lacoste, 2012; Lechner et al., 2016; Soppe et al., 2014) and horizontal (Choi et al., 2010; Hannachi \& 
Coléno, 2012) coopetition, and with different levels of risk, costs, and innovativeness (Fernandez, Le Roy \& Chiambaretto, 2018; Bez \& Chesbrough, 2020). Most prior research, however, focused either on the management of dyadic coopetition (Bengtsson \& Kock, 2000; Dagnino \& Padula, 2002; Le Roy \& Fernandez, 2015) or oligo-coopetition with a moderating third party (Planko, Chappin, Cramer, and Hekkert, 2019, Bez and Chesbrough, 2020, Smiljic, 2020), while the presented results provide insights into the management and organizational designs of oligo-coopetition strategies in the absence of a moderating third party. Second, our results contribute to prior knowledge on organizational design and management of coopetition. We highlight different organizational designs and different uses of management principles for each oligo-coopetition strategy. We further show how companies manage their coopetitive strategy differently according to project risks, costs, and innovativeness. Third, in contradiction to past research, we show, that companies can manage oligo-coopetition for very innovative projects even in the absence of a moderating third-party by cutting projects in sub-tasks and combining SPTs and selective sub-CPTs for high technology sub-tasks. Fourth, our research contributes to research on coopetition for innovation. We highlight a fully counter-intuitive view in which coopetitors have a deep interest in imposing and sharing their technology in the sub-CPTS designed for complex and very innovative sub-tasks.

\subsection{Managerial implications}

The managerial implications of the research are relatively clear. At the strategic level, it is useful to create a common team for all projects in oligo-coopetition. At the operational level, it is important to manage these projects according to their risks, costs, and innovativeness. If the risks, costs and innovativeness are low or moderate, coordination at the operational level should be led by the company with the most significant share in the project. If risks, costs, and innovativeness are high, it is helpful to separate the project into different subtasks and to 
combine SPTs and sub-CPTs. Such sub-CPTs have to include only representatives of coopetitors with in-depth expertise on the individual subtasks. Once a company is involved in a subgroup, its interest is to impose its technology, as this enables it to obtain feedback from competitors on how to improve it.

\subsection{Methodological contributions}

The adoption of the FPMA being still in a developing stage (Bouncken et al., 2021a), our research contributes to its development and application in several ways (Sinkovics, 2018; Bouncken \& Barwinski, 2020). First, we followed earlier suggestions (Bouncken et al., 2021a) and provide evidence of integration of the FPMA with longitudinal studies. This approach allows researchers to anticipate future changes (Bouncken et al., 2021a) by generating an objective theoretical framework which is then compared to and corroborated with qualitative data to study the evolution of patterns and identify potential "mismatches" (Bouncken et al., 2021; de Haan and Rotmans, 2011; Konig et al., 2019). Second, our experience shows that the research framework of the FPMA can be composed of three phases, and each phase can be the result of an iterative approach, which is the foundation of the FPMA (Sinkovics, 2018).

\subsection{Limitations of research and future research directions}

The results of our research should be understood in relation to its limitations. The most obvious limitation is that our case study concerns only one industry, i.e., OGEP. Further studies in other industries are needed to expand the comprehension of the applicability of the results. A second limitation lies in the difficulty in observing in situ operations. More generally, this research shows that it is important to study oligo-coopetition as a specific phenomenon. The results show that the ways of managing oligo-coopetition are similar to but still differ from managing dyadic coopetition. Further research is needed, as many questions remain. How are decisions made in strategic committees? Are there recurring conflicts? How 
are these conflicts managed? Similarly, a more detailed analysis of how knowledge exchanges occur at the operational level, particularly in the case of the technology co-development strategy, should be carried out. It is paradoxical to push technology into a project to have the opportunity to share it when partners are also competitors. It is also paradoxical for competitors to agree to strengthen a competitor's technology within a project since it also strengthens that competitor's technology and reputation. This paradox in situations of oligocoopetition is, in itself, a subject for future research.

Finally, as other qualitative research methods, the FPMA comes along with the common concerns regarding the generalizability of findings resulting from qualitative analysis (Bouncken et al., 2021a). As the FPMA, however, enhances qualitative rigor by linking and iterating between theory and observation (Bouncken et al., 2021b), we call for a broader application of this method in business and management research. As such, the FPMA can be applied in, for instance, longitudinal single/multiple-case studies. Furthermore, we recommend scholars to adopt historical narration to present the results, and to use the FPMA to organize their results by explicitly highlighting the different iterative phases.

\section{References}

Bengtsson, M., Raza-Ullah, T., \& Vanyushyn, V. (2016). The coopetition paradox and tension: The moderating role of coopetition capability. Industrial Marketing Management, $53(1), 19-30$.

Bez, S.M., \& Chesbrough, H. (2020). Competitor Collaboration Before a Crisis. Research Technology Management, 63(3), 42-48.

Bouncken, R.B., \& Fredrich, V. (2012). Coopetition: Performance implications and management antecedents. International Journal of Innovation Management, 16(5), 1-28.

Bouncken, R.B., \& Barwinski, R. (2020). Shared digital identity and rich knowledge ties in global 3D printing-A drizzle in the clouds? Global Strategy Journal, 11(1), 81-108. 
Bouncken, R.B., Fredrich, V., \& Kraus, S. 2020. Configurations of firm-level value capture in coopetition. Long Range Planning, 53(1), 101869.

Bouncken, R.B., Fredrich, V., Ritala, P., \& Kraus, S. (2020). Value-creation-captureequilibrium in new product development alliances: A matter of coopetition, expert power, and alliance importance. Industrial Marketing Management, 90, 648-662.

Bouncken, R.B., Fredrich, V., \& Kraus, S. (2020). Configurations of firm-level value capture in coopetition. Long Range Planning, 53(1), 101869.

Bouncken, R.B., Qiu, Y., \& García, F.J.S. (2021a). Flexible pattern matching approach: Suggestions for augmenting theory evolvement. Technological Forecasting and Social Change, 167, 120685.

Bouncken, R.B., Qiu, Y., Sinkovics, N., \& Kürsten, W. (2021b). Qualitative research: extending the range with flexible pattern matching. Review of Managerial Science, 15, $251-273$.

Brandenburger, A., \& Nalebuff, B. (1996). Coopetition. New York: Doubleday Publishing.

Brooks, J., \& King, N. (2014). Doing template analysis: evaluating an end of life care service. Sage research methods cases.

Chen, M.-J. (2008). Reconceptualizing the competition-cooperation relationship: A transparadox perspective. Journal of Management Inquiry, 17(4), 288-304.

Chiambaretto, P., Bengtsson, M., Fernandez, A.-S., \& Näsholm, M.H. (2020). Small and large firms' trade-off between benefits and risks when choosing a coopetitor for innovation. Long Range Planning, 53(1), 101876.

Chiambaretto, P., \& Dumez, H. (2016). Toward a typology of coopetition: a multilevel approach. International Studies of Management \& Organization, 46(2-3), 110-129. 
Chiambaretto, P., Massé, D., \& Mirc, N. (2019). “All for One and One for All?”-Knowledge broker roles in managing tensions of internal coopetition: The Ubisoft case. Research Policy, 48(3), 584-600.

Choi, P., Garcia, R., \& Friedrich, C. (2010). The drivers for collective horizontal coopetition: a case study of screwcap initiatives in the international wine industry. International Journal of Strategic Business Alliances, 1(3), 271-290.

Czakon, W., Srivastava, M. K., Le Roy, F., \& Gnyawali, D. 2020. Coopetition Strategies: Critical Issues and Research Directions. Long Range Planning, 53(1), 101948.

Czakon, W., Niemand, T., Gast, J., Kraus, S., \& Frühstück, L. (2020). Designing coopetition for radical innovation: An experimental study of managers' preferences for developing self-driving electric cars. Technological Forecasting and Social Change, 155, 119992.

Dagnino, G., \& Padula, G. (2002). Coopetition strategy: A new kind of interfirm dynamics for value creation. Paper presented at the The European Academy of Management Second Annual Conference-Innovative Research in Management, Stockholm.

de Haan, J. H., \& Rotmans, J. (2011). Patterns in transitions: understanding complex chains of change. Technological forecasting and social change, 78(1), 90-102.

Dowling, M., Roering, W., Carlin, B., \& Wisnieski, J. (1996). Multifaceted relationships under coopetition description and theory. Journal of Management Inquiry, 5(2), 155-167.

Dumez, H. (2016). Comprehensive research: a methodological and epistemological introduction to qualitative research. Copenhagen: Copenhagen Business School Press.

Eisenhardt, K. M. (1989). Building theories from case study research. Academy of Management Review, 14(4), 532-550.

Enberg, C. (2012). Enabling knowledge integration in coopetitive R\&D projects: The management of conflicting logics. International Journal of Project Management, 30(7), $771-780$. 
Estrada, I., Faems, D., \& de Faria, P. (2016). Coopetition and product innovation performance: The role of internal knowledge sharing mechanisms and formal knowledge protection mechanisms. Industrial Marketing Management, 53(1), 56-65.

Fernandez, A.-S., \& Chiambaretto, P. (2016). Managing tensions related to information in coopetition. Industrial Marketing Management, 53(1), 66-76.

Fernandez, A.-S., Chiambaretto, P., Le Roy, F., \& Czakon, W. (2018). Routledge Companion to Coopetition Strategies. New York: Routledge.

Fernandez, A.-S., Le Roy, F., \& Chiambaretto, P. (2018). Implementing the right project structure to achieve coopetitive innovation projects. Long Range Planning, 51(2), 384-405.

Fernandez, A.-S., Le Roy, F., \& Gnyawali, D. R. (2014). Sources and management of tension in coopetition case evidence from telecommunications satellites manufacturing in Europe. Industrial Marketing Management, 43(2), 222-235.

Gast, J., Gundolf, K., Harms, R., \& Collado, E. M. (2019). Knowledge management and coopetition: How do cooperating competitors balance the needs to share and protect their knowledge? Industrial Marketing Management, 77, 65-74.

Gernsheimer, O., Kanbach, D.K., \& Gast, J. (2021). Coopetition research - A systematic literature review on recent accomplishments and trajectories. Industrial Marketing Management, 96, 113-134.

Gnyawali, D. R., \& Park, B. (2009). Coopetition and technological innovation in small and medium-sized enterprises: A multilevel conceptual model. Journal of Small Business Management, 47(3), 308-330.

Gnyawali, D. R., \& Park, B. (2011). Coopetition between giants: Collaboration with competitors for technological innovation. Research Policy, 40(5), 650-663.

Hamel, G., Doz, Y., \& Prahalad, C. (1989). Collaborate with your competitors. Harvard Business Review, 67(1), 133-139. 
Hannachi, M., \& Coléno, F. (2012). How to adequately balance between competition and cooperation? A typology of horizontal coopetition. International Journal of Entrepreneurship and Small Business, 17(3), 273-289.

Hoffmann, W., Lavie, D., Reuer, J. J., \& Shipilov, A. (2018). The interplay of competition and cooperation. Strategic Management Journal, 39(12), 3033-3052.

Jakobsen, S. (2020). Managing tension in coopetition through mutual dependence and asymmetries: A longitudinal study of a Norwegian R\&D alliance. Industrial Marketing Management, 84, 251-260.

König, M., Ungerer, C., Baltes, G., \& Terzidis, O. (2019). Different patterns in the evolution of digital and non-digital ventures' business models. Technological Forecasting and Social Change, 146, 844-852.

Lacoste, S. (2012). "Vertical coopetition": The key account perspective. Industrial Marketing Management, 41(4), 649-658.

Lechner, C., Soppe, B., \& Dowling, M. (2016). Vertical coopetition and the sales growth of young and small firms. Journal of Small Business Management, 54(1), 67-84.

Le Roy, F., \& Czakon, W. (2016). Managing coopetition: the missing link between strategy and performance. Industrial Marketing Management, 53(1), 3-6.

Le Roy, F., \& Fernandez, A. S. (2015). Managing Coopetitive Tensions at the Working-group Level: The Rise of the Coopetitive Project Team. British Journal of Management, 26(4), 671-688.

Le Roy, F., Fernandez, A.-S., \& Chiambaretto, P. (2018). From strategizing coopetition to managing coopetition. In FernandezA.-S., Chiambaretto, P., Le Roy, F., \& Czakon, W. (Eds.), The Routledge Companion to Coopetition Strategies. Routledge, New York, NY: $36-46$. 
McLeod, J., \& Thomson, R. (2012). Qualitative longitudinal research. In J. Goodwin (Ed.), SAGE Biographical Research: Starting Points, Debates and Approaches (Vol. 1, pp. 319342). Thousand Oaks: Sage Publications Inc.

Pellegrin-Boucher, E., Le Roy, F., \& Gurău, C. (2013). Coopetitive strategies in the ICT sector: Typology and stability. Technology Analysis and Strategic Management, 25(1), 7189.

Pellegrin-Boucher, E., Le Roy, F., \& Gurău, C. (2018). Managing selling coopetition: a case study of the ERP industry. European Management Review, 15(1), 37-56.

Planko, J., Chappin, M. M., Cramer, J., \& Hekkert, M. P. (2019). Coping with coopetitionFacing dilemmas in cooperation for sustainable development: The case of the Dutch smart grid industry. Business strategy and the environment, 28(5), 665-674.

Quintana-Garcia, C., \& Benavides-Velasco, C. (2004). Cooperation, competition, and innovative capability: A panel data of European dedicated biotechnology firms. Technovation, 24(12), 927-938.

Rajala, A., \& Tidström, A. (2017). A multilevel perspective on organizational buying behavior in coopetition-an exploratory case study. Journal of Purchasing and Supply Management, 23(3), 202-210.

Ritala, P. (2012). Coopetition strategy: When is it successful? Empirical evidence on innovation and market performance. British Journal of Management, 23(3), 307-324.

Ritala, P. 2019. Coopetition and market performance. In A.-S. Fernandez, P. Chiambaretto, F. Le Roy, \& W. Czakon (Eds.), The Routledge Companion to Coopetition Strategies: 339347. New York, NY: Routledge.

Ritala, P., Golnam, A., \& Wegmann, A. (2014). Coopetition-based business models: The case of Amazon.com. Industrial Marketing Management, 43(2), 236-249. 
Ritala, P., Huizingh, E., Almpanopoulou, A., \& Wijbenga, P. (2017). Tensions in R\&D networks: Implications for knowledge search and integration. Technological Forecasting and Social Change, 120, 311-322.

Ritala, P., \& Hurmelinna-Laukkanen, P. (2009). What's in it for me? Creating and appropriating value in innovation-related coopetition. Technovation, 29(12), 819-828.

Ritala, P., \& Sainio, L.-M. (2014). Coopetition for radical innovation: Technology, market and business-model perspectives. Technology Analysis and Strategic Management, 26(2), 155-169.

Rouyre, A., \& Fernandez, A.-S. (2019). Managing Knowledge Sharing-Protecting Tensions in Coupled Innovation Projects among Several Competitors. California Management Review, 62(1), 95-120.

Schiavone, F., \& Simoni, M. (2011). An experience-based view of coopetition in R\&D networks. European Journal of Innovation Management, 14(2), 136-154.

Sinkovics, N. (2018). Pattern matching in qualitative analysis. The sage handbook of qualitative business and management research methods, 468-485.

Smiljic, S. (2020). Beyond the dyad: role of non-competitive partners in coopetitive R\&D projects. International Journal of Innovation Management, 2040006.

Soppe, B., Lechner, C., \& Dowling, M. (2014). Vertical coopetition in entrepreneurial firms: theory and practice. Journal of Small Business and Enterprise Development, 21(4), 548564.

Tidström, A. (2014). Managing tensions in coopetition. Industrial Marketing Management, 43(2), 261-271.

Tidström, A., \& Rajala, A. (2016). Coopetition strategy as interrelated praxis and practices on multiple levels. Industrial Marketing Management, 58, 35-44. 
Yami, S., \& Nemeh, A. (2014). Organizing coopetition for innovation: The case of wireless telefommunication sector in Europe. Industrial Marketing Management, 43(2), 250-260.

Yin, R. K. (2009). Case study research: Design and methods (4th ed.). Thousand Oaks: Sage Publications. 